\title{
IN-THE-FIELD PID RELATED EXPERIENCES
}

\author{
F. Martínez-Moreno ${ }^{(1)^{*}}$, G. Figueiredo ${ }^{(2)}$, E. Lorenzo $^{(1)}$ \\ ${ }^{(1)}$ Grupo de Sistemas Fotovoltaicos, Instituto de Energía Solar - Universidad Politécnica de Madrid \\ (IES-UPM), Ctra. Valencia km 7. Campus Sur UPM, ETSI Sistemas de Telecomunicación, 28031 \\ Madrid, Spain

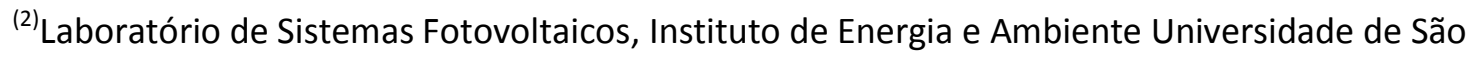 \\ Paulo (IEE-USP), Cidade Universitária, Av. Prof. Luciano Gualberto, 1289, 05508-900 São Paulo, \\ Brazil
}

*Corresponding author: francisco.martinez@ies.upm.es

\begin{abstract}
Potential induced degradation could considerably decrease the performance of photovoltaic systems which operate at high DC voltages. Nonetheless, methodologies for dealing with it in field are not clearly yet defined. This work explains the kinetics of this phenomenon in the field and presents an assessment of its occurrence, detection and prediction in real PV installations. Measurements of the instantaneous operating voltages of the photovoltaic module as a verification routine and predictive maintenance is proposed here as a reasonable and most accurate way of analyzing the actual power losses of the photovoltaic system related to this kind of degradation, as well as detecting and predicting it. Potential induced degradation prevention and recovery have also been carried out by the application of reverse voltage during the night, showing the validity of this technique. A literature review for the PID dynamics of different kinds of photovoltaic cell technologies and development of PID test methodologies and standards is also presented.
\end{abstract}

Keywords: Potential Induced Degradation, Operating voltage, In-the-field PID detection, In-thefield PID prediction, PID effective power losses, Predictive Maintenance.

\section{INTRODUCTION}

Potential Induced Degradation (PID) refers to a loss in the PV module efficiency caused by the high potential (voltage to ground) the solar cells are subjected to during their normal operation [1]. In PV arrays consisting of strings of several series-connected modules, the module potential depends on the grounding configuration of the array (floating or grounded on one terminal or in the center), the inverter switching topology and the position of the module. Whatever the case, the potential is maximum at the terminals (poles) of the string. 
The potential gives rise to leakage currents (LC) that flow to earth from the cells through the module insulation, package, frame grounding points and mechanical support. In turn, the LC leads to the accumulation of a charge trapped on the active layer. Cells with a positive potential are affected by a negative charge, which is mainly made up of electrons; while cells with a negative potential are affected by a positive charge, which is mainly made up of $\mathrm{Na}^{+}$ions -for standard $\mathrm{p}$ based cells- always present on the soda-lime glass front cover of the module [2], [3] and the composition of the anti-reflective coating (ARC). This is exactly the case in standard c-Si modules located at the negative pole of floating voltage arrays, which predominates in current PV-plant market. These ions, helped by a particular kind of crystallographic defect known as stacking faults (SF), are able to shunt the p-n junction of the cell that has been subject to PID formation. The process is particularly significant in the early morning when the front glass is covered with dew, which increases the conductivity of the LC path. Later, irradiance makes dew evaporate, thus decreasing conductivity and causing the ions to recover their equilibrium positions. So PID recovery takes place aided by the increase in temperature and irradiance. The final in-the-field occurrence of PID depends on the balance between PID formation and recovery forces, which depends not only on the characteristics of the PV module but also on the climatic conditions of the location.

Current PID-related test standards address the PID formation but not the PID recovery processes, so modules that have failed in these tests might not necessarily develop PID in the field. Hence the occurrence of PID in the field is an open question as is the need to implement counteractive measures (PV system grounding or/and reverse polarization during the night). An appealing possibility consists of being diligent with periodic predictive maintenance. "c-Si PID degradation is generally reversible and actions can be taken post-operation. It usually makes more economic sense to use yearly maintenance measurements to detect the existence or absence of PID and then take action only if necessary" [4]. This opinion is in agreement with our experience. Although feasible PID detection means that routine maintenance practices are necessary, implementing the surveillance allows the PID to be detected early and, if necessary, to adopt appropriate measures before irreversible degradation sets in, due to electrochemical corrosion, takes place.

Our work only focuses on early PID detection for c-Si conventional modules because this technology dominates the PV market with around 90\% share worldwide [5]-[8]. Different alternatives for in-the-field PID observation in real PV plants were analyzed and it was found that the contrast between the instantaneous operating voltages of the modules at the extremes of the string (positive and negative poles) is more representative to detect PID than other electrical parameters. The procedure is easy to implement in standard predictive maintenance and routine monitoring procedures and it allows not only the detection of PID but also the observation of PID time evolution which provides a way of anticipating the occurrence of PID. The trick is to install module specimens with previous artificially induced PID at the negative pole of a representative number of PV strings. Then, the improvement in PID on these modules (that is, the instantaneous operating voltage of the modules concerned increases) is interpreted as the mechanisms of PID recovery dominating those related to PID formation under the specific climatic conditions of the 
location and, consequently, the occurrence of future PID is excluded. The opposite is also true: a worsening PID indicated by a progressive decrease in the instantaneous operating voltage is taken as a sign that PID is likely to occur.

\section{PID REVIEW}

Potential was identified as a stress factor in 1978 for inclusion in the qualification tests by the Jet Propulsion Laboratory [9]. However, a test for measuring the durability of the continuous system bias was not included in the qualification standards at that time as it was deemed too stressful [10]. Degradation mechanisms resulting from the stress exerted by system bias voltage depends on the particular module technology. Electrochemical corrosion of transparent conductive oxide (TCO) related to negative potential was described in 1989 [11]. It is associated with $\mathrm{Na}^{+}$migration and the presence of moisture (from the extremities of the modules) accelerated as the trapped water vapor increases the electrical conductivity and the LC [3]. In order to avoid this phenomenon, thin-film manufacturers normally produce unframed modules to maximize the resistance of the LC path between the cells and the ground. Furthermore, manufacturers are very likely to require the grounding of the negative terminal of the PV arrays to fully avoid negative potential in the cells.

Another degradation mechanism, this time associated to positive potential, is the surface polarization effect that affects c-Si interdigitated back-contact solar cells (IBC). First described in 2005 [12], this effect consists of the accumulation of negative charge on the surface of the ARC which attracts positively charged light-generated holes to the front where they recombine with $\mathrm{n}$ type silicon electrons. In other words, this effect increases the surface-recombination rate. Interestingly, the surface polarization effect is found to be reversible and it is avoidable by grounding the positive terminal of the PV arrays, which imposes negative potential to all the cells. Later studies into PID in IBC cells have confirmed the relation between this process and the increased surface recombination, which is attributed to a degradation of the front passivation layer due to ion drift induced damage of the dielectric/Si interface [13].

The term "PID" was introduced in 2010 [14] in a paper dealing with the degradation observed in standard -front and rear contact- p-type c-Si technology. Degradation appears to be associated with negative potential which give rise to cell shunting since both the shunt resistance and the fill factor decrease, which speculatively suggested the incorporation of deleterious ions in the active layer of the cell [15]. That was later confirmed when observing, first, that cell-shunted regions show an accumulation of $\mathrm{Na}^{+}$and other alkali metals on the surface and within the $\operatorname{SiN}_{\mathrm{x}}$ ARC layer [16], [17] and, second, that shunts are also correlated with a kind of crystallographic defect called Stacking Faults (SF) which provide diffusion channels for $\mathrm{Na}^{+}$across the $\mathrm{p}-\mathrm{n}$ junction [18], [19]. The experimental findings were later corroborated and explained through computational simulations

[20]: it is energetically favorable for $\mathrm{Na}^{+}$to segregate at the SF. Although a large electrical potential is required to transport $\mathrm{Na}$ atoms from the source (which could be the front cover glass or the $\mathrm{SiN}_{\mathrm{x}}$ 
$\mathrm{ARC}$ ) to the $\mathrm{SiN}_{\mathrm{x}} / \mathrm{SiO}_{\mathrm{x}} / \mathrm{Si}$ interface, they then spontaneously diffuse into the SF creating an electrically conductive 2D layer and causing $p$-n junction short-circuiting inside the PV cell.

PID has also been detected in standard n-type c-Si technology and it is suspected that the effect in this case is not brought about by $\mathrm{Na}^{+}$diffusion, as in $\mathrm{p}$-type solar cells, but by positive charges mostly $\mathrm{K}^{+}$centers- trapped in the $\mathrm{SiN}_{\mathrm{x}}$ layer. The trapped charges lead to an increasing concentration of the minority carrier in the $p$-layer which consequently increases the charge recombination rate on the surface [21].

In common with the occurrence of PID in p-type and n-type PV cells is that both effects, $\mathrm{Na}^{+}$ diffusion and $\mathrm{K}^{+}$center trapping, are reversible and avoidable by grounding the negative terminal of the PV arrays, which automatically imposes positive potential on all of the cells. A comprehensive review of the underlying mechanisms of PID has recently been published [1].

PID due to shunting and/or polarization can be reversed by the natural tendency of the dislocated ions to recover their equilibrium positions once the LC causing the PID ceases. This natural tendency can be observed when a degraded PV module is stored at room temperature and in the dark as $P_{\text {STC }}$ recovers slightly over time. This recovery can be accelerated by heat since it increases the mobility of the ion [14], [22], [23]; as does exposure to sunlight, which is probably related to the increase in ARC conductivity during illumination [24].

\subsection{Kinetic of the PID in the field.}

As regards the field, floating PV arrays are usually preferred in comparison to grounded ones for reasons of electrical safety: floating PV arrays are intrinsically safe should there be a first groundfault because the corresponding default current is strongly limited by the isolation resistance of the PV array. Moreover, floating PV arrays minimize the system voltage to ground and can be connected to the distribution grid by means of transformerless inverters, which is why most standard (front and back contact) c-Si technology PV arrays are just floating ones. Furthermore, PV module frames are always grounded as protection against indirect contacts and lightning.

PID proceeds as a dynamic process in these standard c-Si floating PV arrays, somewhat as a trial of strength between PID formation and PID recovery: LC between cells at negative potential and ground, causing the displacement of positive ions, depends on the voltage applied and the resistance of the path between the affected cells and the grounded frame. The surface of the front glass is the key pathway under outdoor operating conditions [25], [26]. Early in the morning the glass is covered with dew, which increases the conductivity significantly, while irradiance gives rise to PV system open-circuit/operating voltage. Under these conditions, which also happen on rainy days, the path resistance is mainly due to the bulk of the front glass and the encapsulation, and reaches the minimum value. Hence, LC increases and PID tends to form. Interestingly, surface soiling also has a role: it acts as a storage matrix for humidity, like a sponge, and extends the surface grounding period with high LC [27]. As the day goes on, irradiance makes the dew 
evaporate, the LC path resistance takes place all over the surface of the glass and the value of this resistance increases significantly (the typical distance from the frame to the border cells is a few $\mathrm{cm}$, i.e. several times larger than the thickness of the glass), leading to a halt in LC. Then, PID recovery takes place helped by PV module operating temperature and irradiance. During the night, the PV voltage is null so that PID also tends to recover even in case of dew. PID recovery during the day at elevated temperatures is typically more relevant than recovery during the night at low temperatures [28]. However, PID recovery during the night can be accelerated by reverse polarity, i.e. applying a positive voltage between the PV modules and the ground. This is the fundament of all commercial anti-PID devices [14], [23].

As a final result, PID will develop if its formation systematically prevails against recovery: PID will remain in the PV array lowering its energy production and increasing the mismatch losses, which may origin the formation of hot-spots. The opposite is also true: PID will simply not develop if its recovery prevails systematically against the formation of PID. This balance usually becomes clear after one year of continuous operation and depends on the intrinsic characteristics of the PV module technology, PV system grounding scheme and PV system operating voltage (which varies in practice from about $320 \mathrm{~V}$, in monophasic systems connected to $230 \mathrm{~V}$ distribution grids, to $1500 \mathrm{~V}$, on recent large multi-megawatt PV plants). If PID continues for a long time, irreversible electrical corrosion might also take place [2].

\subsection{PID testing and standards}

PID was detected in commercial standard PV plants in $2009^{1}$. Since then, a lot of work has been done to develop PID-free modules. All related proposals have the attempt to increase the resistance of the LC pathways in common, which can be done at the cell level by selecting the appropriate crystal orientation [29], ARC coating [14], [30], [31] or passivation layer [32], [33]; at the module level, manufacturers normally use high resistive encapsulations [34]-[38] or alminosilicate and chemically tempered glass [39]. Along similar lines, the stress test of the PV modules to detect the propensity for PID formation has been carried out since 2010 [2], [14], [40][43] based on different combinations of voltage, temperature and way of reducing the front glass conductivity: humidity or conductive foils. IEC-TS-62804-1:2015 standard tests for detecting the propensity for PID formation in PV modules was launched in 2015 [44] after several years of draft status. This technical instruction describes two different ways of testing, respectively referred to as the climatic chamber and the Al foil methods. In both methods, the two leads of the module are

\footnotetext{
${ }^{1}$ Available literature is not clear as regards the first news on PID in standard technology commercial plants. We, at the IES-UPM, detected PID in November 2008, somewhat by chance, when carrying out a routine reception trial of a particular PV plant located in Cadiz (Spain), within the framework of the due diligence associated to the bank financing of the plant. However, we could not make it public at that time, because we were under a non-disclosure agreement. Other researchers can probably tell similar anecdotes, so we do not dare even to suggest that we discovered PID in standard PV plants. Nevertheless, we mention that here for those interested in PV small history. Whatever the case, the first paper on PID in wafer-based standard p-type technology was published in 2010 and it states that PID was first detected in 2009 and the authors were the engineers of a company that was involved in the construction of the Cadiz PV plant in which we found PID.
} 
shortened and connected to the negative terminal of a high voltage source adjusted to the maximum PV system voltage (normally $1000 \mathrm{~V}$ ) while the module frame is grounded and connected to the positive terminal of the source. The climatic chamber method requires the modules to be stressed for $96 \mathrm{~h}$ at $60^{\circ} \mathrm{C}$ and $85 \%$ relative humidity. The other method is carried out by placing an Al sheet across the front glass surface and the module is stressed for $168 \mathrm{~h}$ at $25^{\circ} \mathrm{C}$. Arguments on the real significance of the test results are still open to discussion. In fact, both test procedures are not comparable as the magnitude of the stress is different. Along similar lines, the variability of test results within a given module design reaches $60 \%$, as revealed by a round-robin test among 5 laboratories [45]. Whatever the case, the correlation between the test results and PID-risk in the field is put into question [46], [47] because the recovery capacity is not addressed in these standard tests. In fact, later in this paper, a case of PV modules that failed these tests but have still not developed PID in the field is presented. We think this is probably very common.

PID recovery capacity has also been tackled in some tests [14], [23], [48] although attempts at predicting the evolution of PID in the field have to date led to inconclusive results. An LC accumulated charge was proposed as PID indicator [49] but it was found not to be directly correlated with the occurrence of PID [50], [51]. Shunt resistance appears to be more correlated with PID [52], [53] but the practical modelling of its progression gave rise to severe difficulties as there is general lack of data on relative humidity across the front glass surface, which is a key parameter of this modelling. Moreover, the occurrence of PID even with the same brand of module and in the same location is far of being uniform [54], which raises doubts into the representativeness of the shunt resistance kinetic observed in specific module specimens and underlying this modelling.

It is worth emphasizing two facts related to PID in c-Si modules. One is because the main parameter affected is shunt resistance, the consequent decrease in efficiency becomes particularly apparent at low irradiances, which has been cited to support propositions for including a criterion at low irradiances into the standard test protocol [55]. The other is that the probability of irreversible degradation is directly related to the PID period [56], [57].

\section{IN-THE-FIELD PID DETECTION}

\subsection{Theory and methods.}

The electrical behaviour of a PV module or a solar cell is traditionally represented by its I-V curve (Fig. 1a, dashed blue line), whose particular shape depends on 5 parameters: the short-circuit current, $I_{\mathrm{SC}}$, the open circuit voltage, $V_{\mathrm{OC}}$, the diode ideality factor, $m$, the series resistance, $R_{\mathrm{S}}$, and the shunt resistance, $R_{\mathrm{SH}}$. The last is the inverse of the I-V curve slope around the short circuit zone. Under normal operating conditions, the modules work close to the maximum power point, $P_{\mathrm{MPP}}$, which corresponds to its respective voltage values, $V_{\mathrm{MPP}}$, and current, $I_{\mathrm{MPP}}$. PID formation in standard c-Si modules mainly translates into a decrease in $R_{S H}$, which has different effects and opens up possibilities for different detection procedures. 
On the one hand, when the affected PV module is considered alone (Fig. 1a, continuous red line), decreasing $R_{\mathrm{SH}}$ translates into a decrease in $P_{\mathrm{MPP}}, I_{\mathrm{MPP}}, V_{\mathrm{MPP}}$ and the ratios $I_{\mathrm{MPP}} / I_{\mathrm{SC}}$ and $V_{\mathrm{MPP}} / V_{\mathrm{OC}}$. Other factors might also affect these parameters, such as shadows, hot-spots, cell cracks, etc., but when PID is responsible for their variation the damage caused in the affected modules has a characteristic pattern. Besides, modules affected by PID are normally located at one of the poles of the string. In case of doubt, the combination of the detection procedures explained below leads to the confirmation of PID occurrence [58]. Hence, measuring I-V curves and analysing some of these parameters represents a possible way of detecting PID. In practice, this procedure requires the string involved to be disconnected from the inverter and recording I-V curves of suspicious PID affected (close to the negative pole) and unaffected (close to the positive pole) modules with commercial I-V tracers. This is not really complex, but the need for disconnection implies that it must be done at specific moments and requires personal intervention. Continuous on-line PID surveillance with this procedure is excluded. Furthermore, the solar cells located at the centre of the PV module are less prone to developing PID than those located at the border. The explanation relies on the shorter distance of the latter to the PV module frame which allows a shorter resistance of the path for the LC between the cells and the frame. It is reflected in a characteristic electroluminescent (EL) image pattern of PID affected modules: it is darker at the border than in the centre. So, EL with conventional CCD cameras is another procedure for detecting PID since the pattern is easily recognized. Besides, taking EL images is not difficult to carry out but it is opportune to remember that EL images must be taken in the dark, which implies a certain practical price: dismantling modules, covering them with opaque tops or doing at night. These facts exclude on-line PID surveillance with this procedure.

On the other hand, when the affected PV module is connected in series with other unaffected ones and the PV array is in operation, differences in $R_{\mathrm{SH}}$ give rise to different operating voltages, $V_{\mathrm{OP}}$, lower in the affected modules than in the unaffected ones (Fig. 1b). This time, the corresponding PID detection procedure, based on monitoring the $V_{\mathrm{OP}}$ differences between the modules at the extreme poles of the string, must be carried out under normal operating conditions (with the inverter delivering energy, the $V_{O P}$ of these modules can be measured with multimeters or dataloggers), thus allowing continuous PID surveillance. It is also easy to implement in practice because " $T$ " shaped quick connectors, to connect PV modules to each other, are widely commercially available. Furthermore, as inhomogeneities among the cells of a same module and the differences in $V_{O P}$ can produce hot-spots, infrared (IR) images taken with commercial thermographic cameras can also help to detect PID on PV arrays in operation.

Similarly, when a PV string with PID affected modules is connected in parallel with other strings without defective modules and the PV array is in operation, there is additional mismatch between the string operating currents which increases even more the array power losses. Nevertheless, for low degradation rates (e.g., only one single module affected by PID in the string) this mismatch can be inappreciable and the defect will remain hidden. To that end, the procedure based on monitoring $V_{\mathrm{OP}}$ differences between the modules at the extreme poles of the string is a more suitable method to detect PID even at its early stages. 




(a)

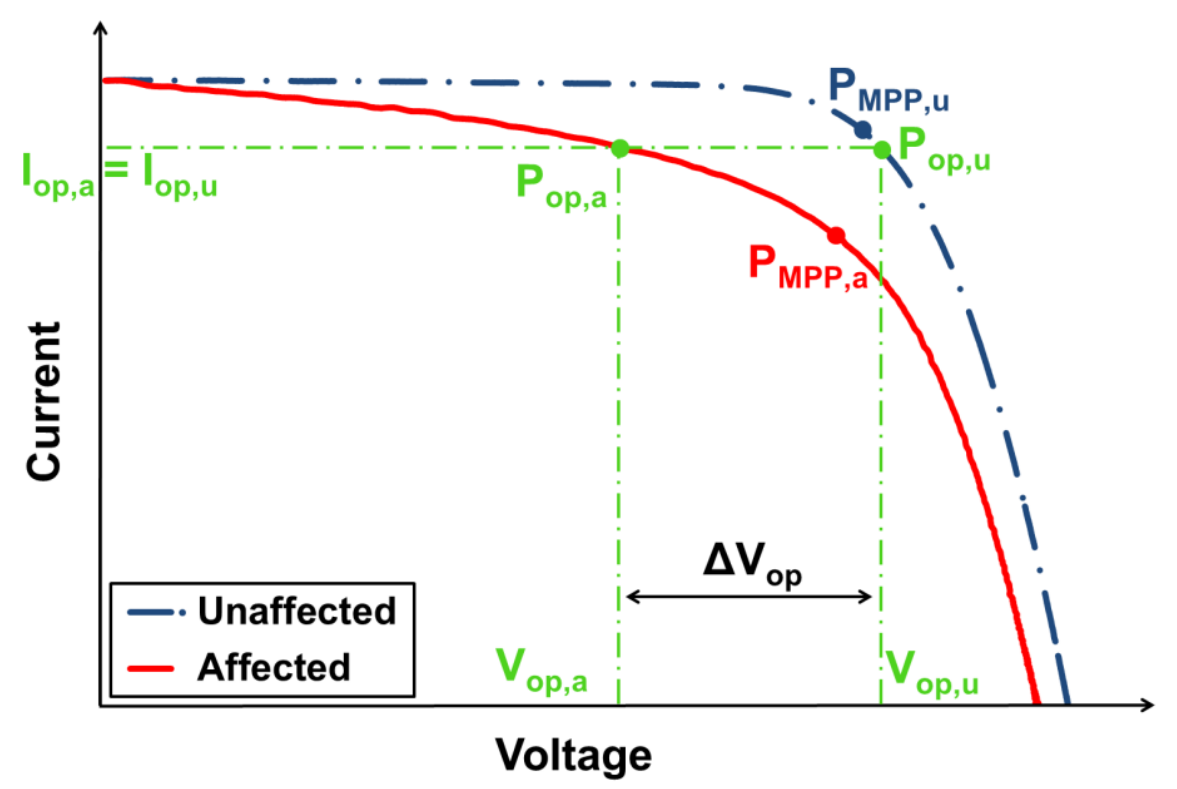

(b)

Fig. 1. (a) I-V curve of a PV module unaffected (dashed blue line) and affected by PID (continuous red line). The shunt resistance, $R_{\mathrm{sh}}$, is the slope at the short-circuit point. PID reduction of $R_{\mathrm{sh}}$ translates into a decrease in $P_{\text {MPP }}, I_{\text {MPP }}$ and $V_{\text {MPP }}$ between the affected (subscript 'a') and the unaffected (subscript ' $u$ ') PV modules when considered alone. (b) A reduction of $R_{\mathrm{sh}}$ related to PID translates into different operating voltages between the affected $\left(V_{o p, a}\right)$ and the unaffected $\left(V_{o p, u}\right)$ PV modules connected in series along the same string. The slight difference between $\mathrm{P}_{\mathrm{MPP}, \mathrm{u}}$ and $\mathrm{P}_{\mathrm{op}, \mathrm{u}}$ represents the losses due to the maximum power point (MPP) tracking strategy of the inverter. 


\subsection{Results and discussion.}

Fig. 2 to Fig. 4 and Table 1 present the results of applying different PID detection procedures to a 24-module string from a floating array at a PID-affected PV plant [58]. It is opportune to mention that this plant is located in Cape Verde, which lacks a specialized research PV infrastructure and transportation is rather difficult. The PV plant was in routine operation for two years before seeking IES-UPM technical assistance. The EL images in Fig. 2 were taken at midnight with a CCD camera (each PV module was polarized at 2 amps with a DC power supply) and show that PID only appears on PV modules (number 2 to 10) on the negative side of the string. The most negative PV module (number 1 ) is an exception because it was changed for a new module just before taking the EL images. The EL images of the PID-affected modules exhibit the aforementioned characteristic pattern (darker at the border).

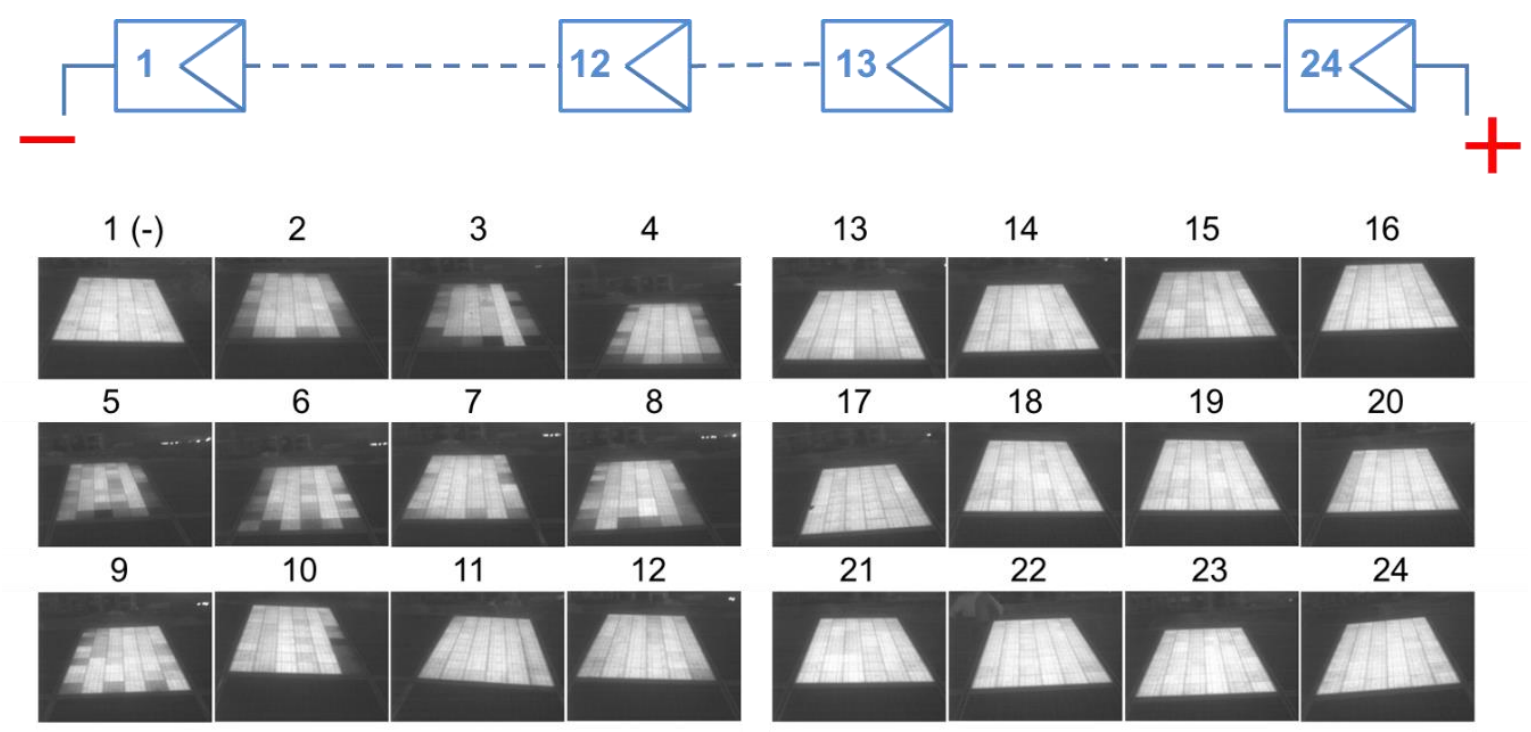

Fig. 2. Example of a PV string affected by PID. (a) PV modules numbered from negative pole $-1-$ to positive pole -24-. (b) EL images of all the modules in the string.

Fig. 3 shows the I-V curves of the affected and the unaffected modules (curve of unconnected individual modules) measured with a commercial I-V tracer. Both curves have been normalized to $I_{\mathrm{SC}}$ and $V_{\mathrm{OC}}$ in order to facilitate their visual contrast. The non-homogeneous development of PID among the solar cells of the same module is translated into the anomalous shaped curve clearly visible around the MPP for the affected module. 


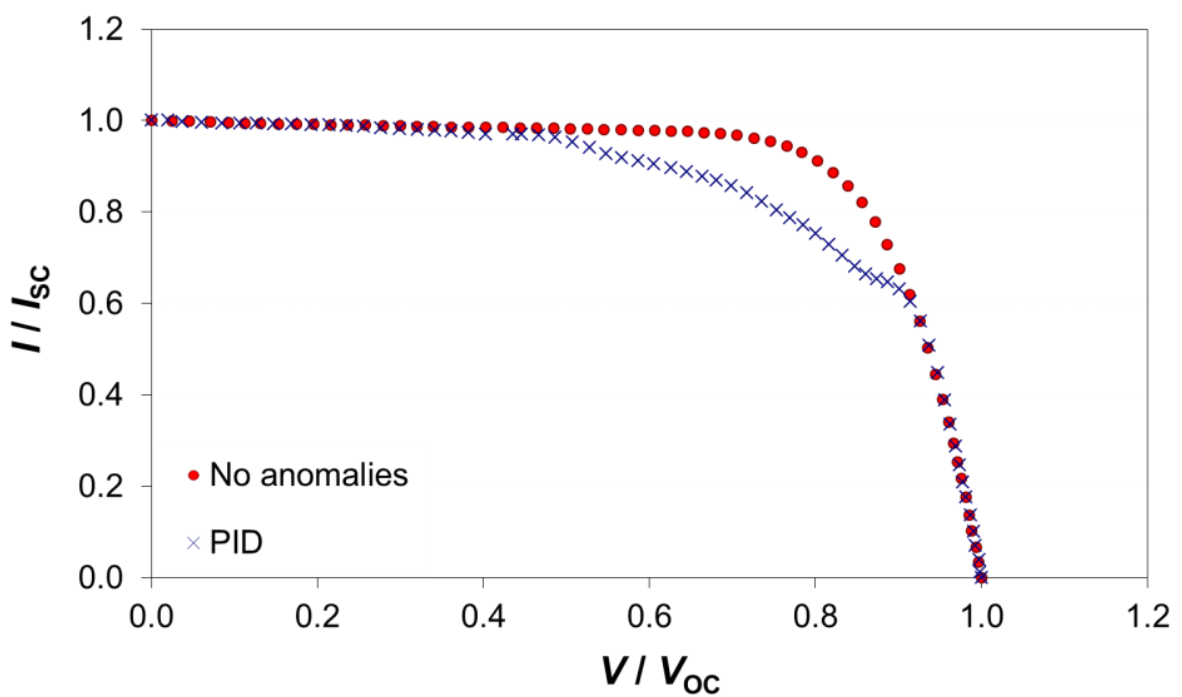

Fig. 3. Normalized IV curve of a module with no anomalies (circles) and normalized IV curve of a module affected by PID (crosses).

Fig. 4 shows (circles) the measured maximum power extrapolated to STC, $P_{M P P}^{*}$ (the superscript * just refers to STC), of each PV module in relation to their nominal values (considered as the STC value of $P_{\text {MPP }}$ on the manufacturer's datasheet, $P_{M P P ~ N O M}^{*}$ ). The I-V curves have been recorded in 10 minutes during a clear day with irradiances of between 998 and $1006 \mathrm{~W} / \mathrm{m}^{2}$ and cell temperatures of between $47.4^{\circ} \mathrm{C}$ and $50.1^{\circ} \mathrm{C}$. Then the curves have been corrected to STC according to IEC 60891 [59] to reduce any discrepancies between measurements due to differences in irradiance and cell temperature (in this particular case, as irradiance and cell temperature variations are very small, these discrepancies could have been negligible). Note that the real power of PID unaffected modules is about $7 \%$ below the nominal value, due to a combination of LID and poor quality control during the procurement phase. So, the decrease in power exclusively due to PID is close to $-10 \%$ in the most affected modules. Fig. 4 also shows (squares) the measured $V_{\mathrm{OP}}$ of all the PV modules, now connected in series under normal operating conditions, in relation to their nominal values (considered as the STC value of $V_{\text {MPP }}$ of the manufacturer's datasheet, $V_{M P P ~ N O M}^{*}$ ). $V_{\mathrm{OP}}$ measurements were performed within a 2 minutes interval and using multimeters connected directly with the " $T$ " shaped quick connectors between the modules, as can be seen in Fig. 5. The outstanding point is that $V_{\mathrm{OP}}$ of each module is not only easy to measure but it also reports with higher accuracy the effective power losses between operating individual modules caused by PID than $P_{M P P}^{*}$ or any other electrical parameter. As can be seen in Table 1, the actual effective power losses during operation reach $-15.2 \%$ while the maximum difference in $P_{M P P}^{*}, V_{M P P}$ and $I_{M P P}$ does not reach $-10 \%$. This is because the effective power losses due to PID, $\Delta \mathrm{P}_{\mathrm{PID}, \mathrm{Eff}}$, include not only the individual power losses related to the phenomenon, $\Delta P_{\mathrm{PID}, \mathrm{P}}$, but also the additional mismatching losses due to connecting modules in

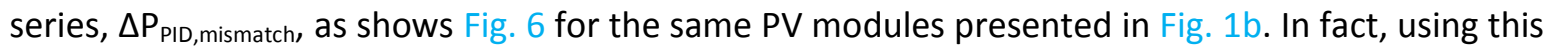
technique allows not only a quick PID detection, before irreversible damages occur, but also to predict the occurrence of PID, as described in the next section. Somewhat surprisingly is that $V_{O P}$ observations are scarcely or even not mentioned in PV module reliability studies [57]. Significantly, the procedure of $V_{\text {op }}$ measurements can be easily incorporated into on-line surveillance procedures. 


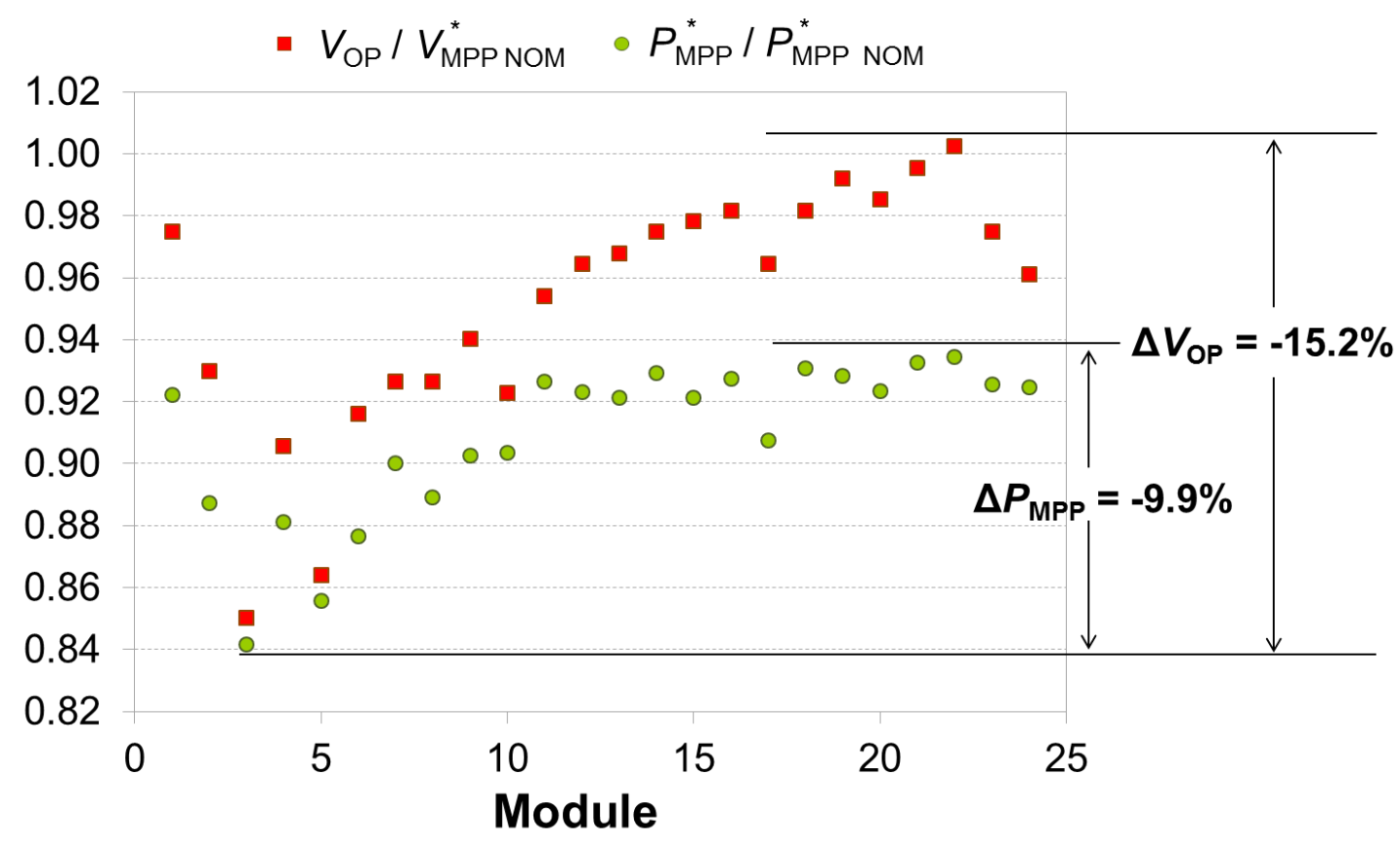

Fig. 4. Peak power corrected to STC, $P_{M P P}^{*}$, and operating voltage, $V_{\mathrm{OP}}$, decrease caused by PID (both variables are normalized). The higher differences measured on $V_{\mathrm{OP}}$ reflect that this variable is a more sensible PID indicator than $P_{M P P}^{*}$.

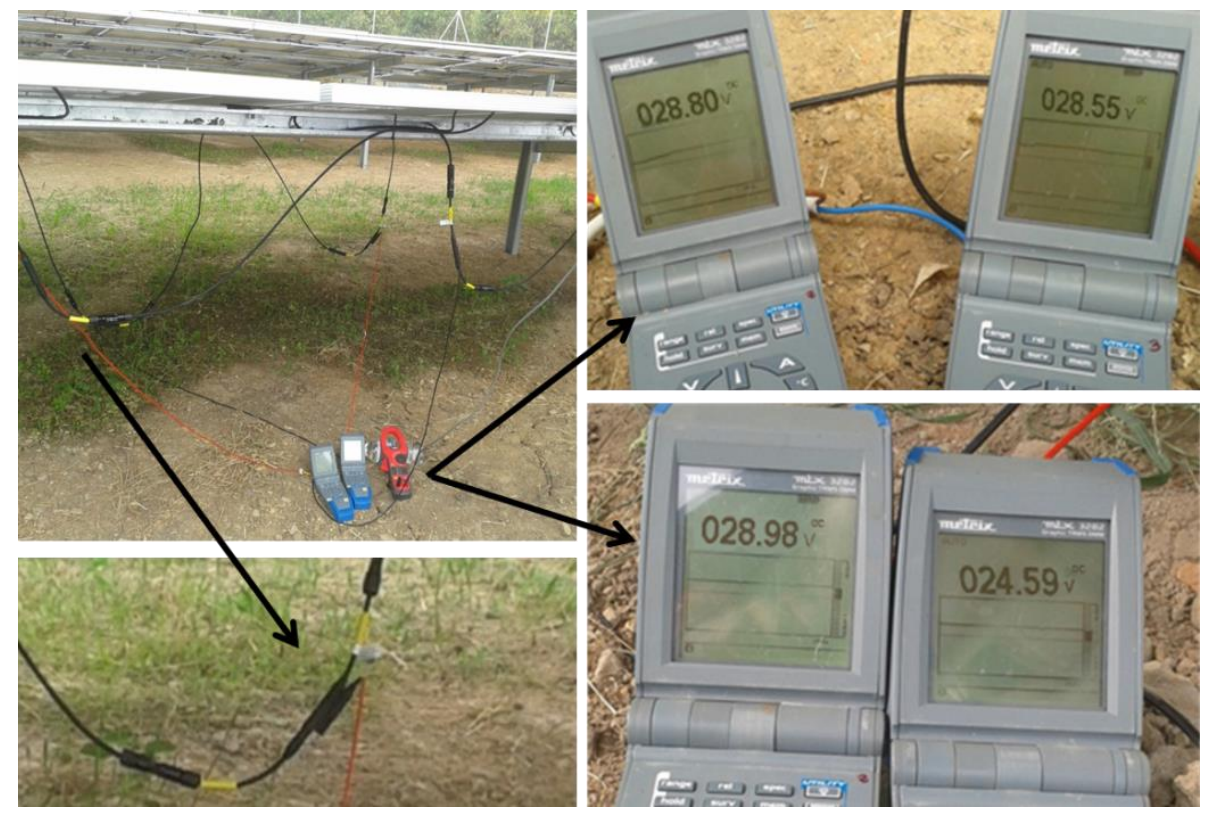

Fig. 5. Example of " $\mathrm{T}$ " shaped quick connectors used to measure the $V_{\mathrm{OP}}$ of modules delivering power to the inverter (left-side). The multimeters (right-side) show different situations: two modules without PID (almost same $V_{\mathrm{OP}}$, up) and one module with PID and other without PID ( $V_{\mathrm{OP}}$ difference close to $15 \%$, down). 


\begin{tabular}{|c|c|c|c|c|c|c|c|}
\hline Position & $I_{S C}^{*}(\mathrm{~A})$ & $V_{O C}^{*}(\mathrm{~V})$ & $P_{M P P}^{*}(\mathrm{~W})$ & $\frac{I_{M P P}}{I_{S C}}$ & $\frac{V_{M P P}}{V_{O C}}$ & $\frac{P_{M P P}^{*}}{P_{M P P ~ N O M}^{*}}$ & $\frac{V_{O P}}{V_{M P P ~ N O M}^{*}}$ \\
\hline 1 & 8.54 & 36.4 & 212.1 & 0.905 & 0.738 & 0.922 & 0.975 \\
\hline 2 & 8.5 & 36.4 & 204.1 & 0.884 & 0.729 & 0.887 & 0.930 \\
\hline 3 & 8.52 & 36.1 & 193.6 & 0.847 & 0.727 & 0.842 & 0.850 \\
\hline 4 & 8.52 & 36.3 & 202.7 & 0.877 & 0.732 & 0.881 & 0.906 \\
\hline 5 & 8.5 & 36.1 & 196.8 & 0.861 & 0.730 & 0.856 & 0.864 \\
\hline 6 & 8.52 & 36.2 & 201.6 & 0.871 & 0.734 & 0.877 & 0.916 \\
\hline 7 & 8.54 & 36.3 & 207 & 0.885 & 0.738 & 0.900 & 0.926 \\
\hline 8 & 8.52 & 36.3 & 204.5 & 0.881 & 0.735 & 0.889 & 0.926 \\
\hline 9 & 8.53 & 36.4 & 207.6 & 0.886 & 0.739 & 0.903 & 0.940 \\
\hline 10 & 8.51 & 36.5 & 207.8 & 0.893 & 0.734 & 0.903 & 0.923 \\
\hline 11 & 8.5 & 36.8 & 213.1 & 0.914 & 0.730 & 0.927 & 0.954 \\
\hline 12 & 8.54 & 36.7 & 212.3 & 0.905 & 0.735 & 0.923 & 0.964 \\
\hline 13 & 8.45 & 36.7 & 211.9 & 0.914 & 0.733 & 0.921 & 0.968 \\
\hline 14 & 8.47 & 36.8 & 213.7 & 0.918 & 0.731 & 0.929 & 0.975 \\
\hline 15 & 8.47 & 36.7 & 211.9 & 0.912 & 0.733 & 0.921 & 0.978 \\
\hline 16 & 8.45 & 36.9 & 213.3 & 0.922 & 0.727 & 0.927 & 0.982 \\
\hline 17 & 8.45 & 36.7 & 208.7 & 0.881 & 0.749 & 0.907 & 0.964 \\
\hline 18 & 8.49 & 36.8 & 214.1 & 0.917 & 0.732 & 0.931 & 0.982 \\
\hline 19 & 8.48 & 36.8 & 213.5 & 0.912 & 0.732 & 0.928 & 0.992 \\
\hline 20 & 8.48 & 36.7 & 212.4 & 0.908 & 0.734 & 0.923 & 0.985 \\
\hline 21 & 8.46 & 36.9 & 214.5 & 0.917 & 0.734 & 0.933 & 0.996 \\
\hline 22 & 8.54 & 36.8 & 214.9 & 0.910 & 0.734 & 0.934 & 1.002 \\
\hline 23 & 8.5 & 36.8 & 212.9 & 0.910 & 0.732 & 0.926 & 0.975 \\
\hline 24 & 8.45 & 36.7 & 212.7 & 0.914 & 0.734 & 0.925 & 0.961 \\
\hline \multicolumn{4}{|c|}{ (Minimum - Maximum) / Maximum (\%) } & -8.1 & -2.9 & -9.9 & -15.2 \\
\hline
\end{tabular}

Table 1. Measurements taken from the 24 modules of a string affected by PID. $I_{S C}^{*}, V_{O C}^{*}$ and $P_{M P P}^{*}$ are obtained from the extrapolation of the measured I-V curves. The ratios of columns 5 and 6 can be calculated directly from the I-V curve measured and the ratio of column 7 is obtained from the extrapolated curve. The ratio related to the measured operating voltage $V_{\mathrm{OP}}$ (column 8 ) is obtained without the need to switch off the system and provides the closest figure to the actual losses due to PID. 


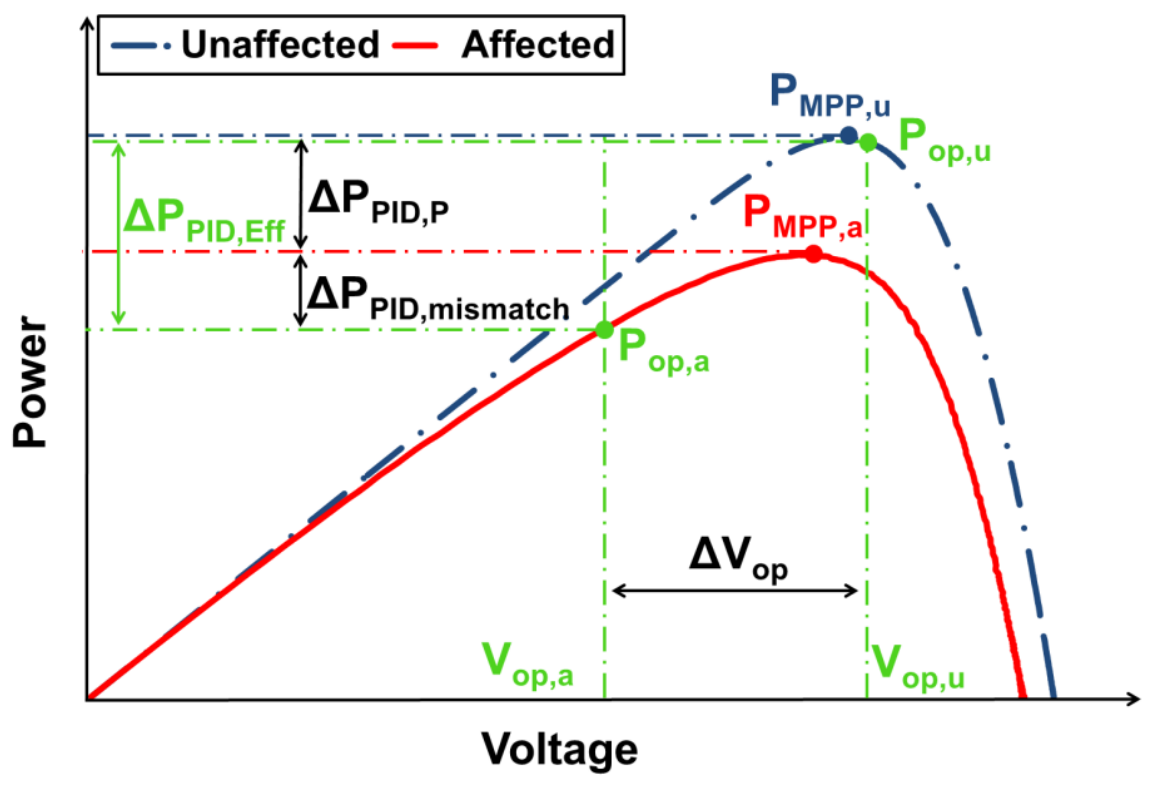

Fig. 6. P-V curves of two modules (PID unaffected: blue dashed line; PID affected: red continuous line). The effective power reduction due to PID, $\triangle \mathrm{P}_{\mathrm{PID}, \mathrm{Eff}}$, has two components: the PID power losses which directly affect to the PV module, $\Delta \mathrm{P}_{\mathrm{PID}, \mathrm{P}}$, and the additional power losses related to the

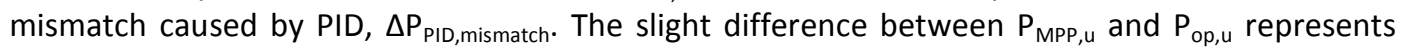
the losses due to the maximum power point tracking (MPPT) strategy of the inverter.

\section{IN-THE-FIELD PID PREDICTION}

\subsection{Theory and methods.}

A PV plant located in the southern hemisphere began its operation in February 2015 and was bought by an investment fund in December of the same year. The plant, made up of PV arrays operating at floating voltage, had not shown particular PID symptoms thus far, although a set of 4 PV modules failed in the climatic chamber IEC-62804 test during the quality checks required by the buyer. Observed degradations of $10.4 \%, 77.8 \%, 89.1 \%$ and $92.1 \%$ gave rise to a suspicion that PID would develop in the future and the IES-UPM technical advisory was asked to mediate in the discussion. Inspired by several PID-related experiments which considered the operating conditions at the site [40] and adopting the aforementioned $V_{O P}$-PID relationship, the in-the-field evolution of the $V_{O P}$ on a sample of 11 modules with previous artificially induced PID (by means of the climatic chamber IEC-62804 procedure) was monitored. These modules were installed at the negative extreme of 11 strings and anti-PID devices, applying $600 \mathrm{~V}$ during the night, were also installed in 6 of these strings (those in italic in Table 2). The $V_{O P}$ of the two modules at the extremes of each string were recorded manually at about midday and once a week, for four months -September to December 2016- the humid season. Because the current is constant for all the modules of the same string, the relative difference between the operating voltages of the extreme modules, $\Delta V_{\mathrm{OP}}=\left(V_{O P}^{-}-V_{O P}^{+}\right) / V_{O P}^{+}$, is interpreted as a reasonable measure of effective PID-degradation. So, 
considering that the module installed in the negative pole of the string is affected by PID and the one installed in the positive pole is unaffected $\Delta V_{O P}=\left(V_{O P, a}-V_{O P, u}\right) / V_{O P, u}$.

\subsection{Results and discussion.}

Table 2 and Fig. 7 show the experimental results. Note that in Table 2 power losses at column 2 and at columns 3 to 19 cannot be compared directly because are different quantities. Column 2


these values, it must be considered that the operating voltage of the PV modules is oscillating continuously due to the MPP search of the inverter, as shown in Fig. 8. The amplitude of the oscillation is larger in the PV modules affected by PID, $\Delta \mathrm{V}_{\mathrm{MPP}, \mathrm{a}}$, than in the unaffected ones, $\Delta \mathrm{V}_{\mathrm{MPP}, \mathrm{u}}$. Therefore, the differences between $\Delta V_{\mathrm{OP}}$ of unaffected and PID affected PV modules also oscillate continuously. In other words, $\Delta V_{\mathrm{OP}}$ is affected by a relatively high-frequency component acting as noise that limits the significance of the individual readings (mainly in the case of manual records in the absence of synchronization, which leads to meaningless records, like those which give rise to negative slopes in the evolution of $\Delta V_{\mathrm{OP}}$ values as observed in Fig. 7). As time integration effectively reduces the noise, the corresponding long-term evolution is significant. Hence, the relevant result here is that all the PV modules, except 1 and 7, are evolving positively (a decrease in PID degradation), showing that PID recovery is greater than PID formation and the occurrence of PID occurrence can, in principle, be excluded at the plant. It also helps to explain why PID has not occurred during the first two years of the PV plant operation and also why the risk of future occurrence is very low.

The two module exceptions correspond to a 97\% (module 1) and 95\% (module 7) initially induced power loss, which seems far from representing real situations in the field. Moreover, the behaviour of these modules is likely affected by the bypass diodes, which causes the modules to short-circuit. As the degradation remains below a certain threshold, it avoids observing a possible positive evolution. In fact, this seems to be the case for module 7 which shows a positive evolution from the third month of the experiment. Unfortunately, the experiment was interrupted when the vendor and the buyer of the plant reached a final agreement. 


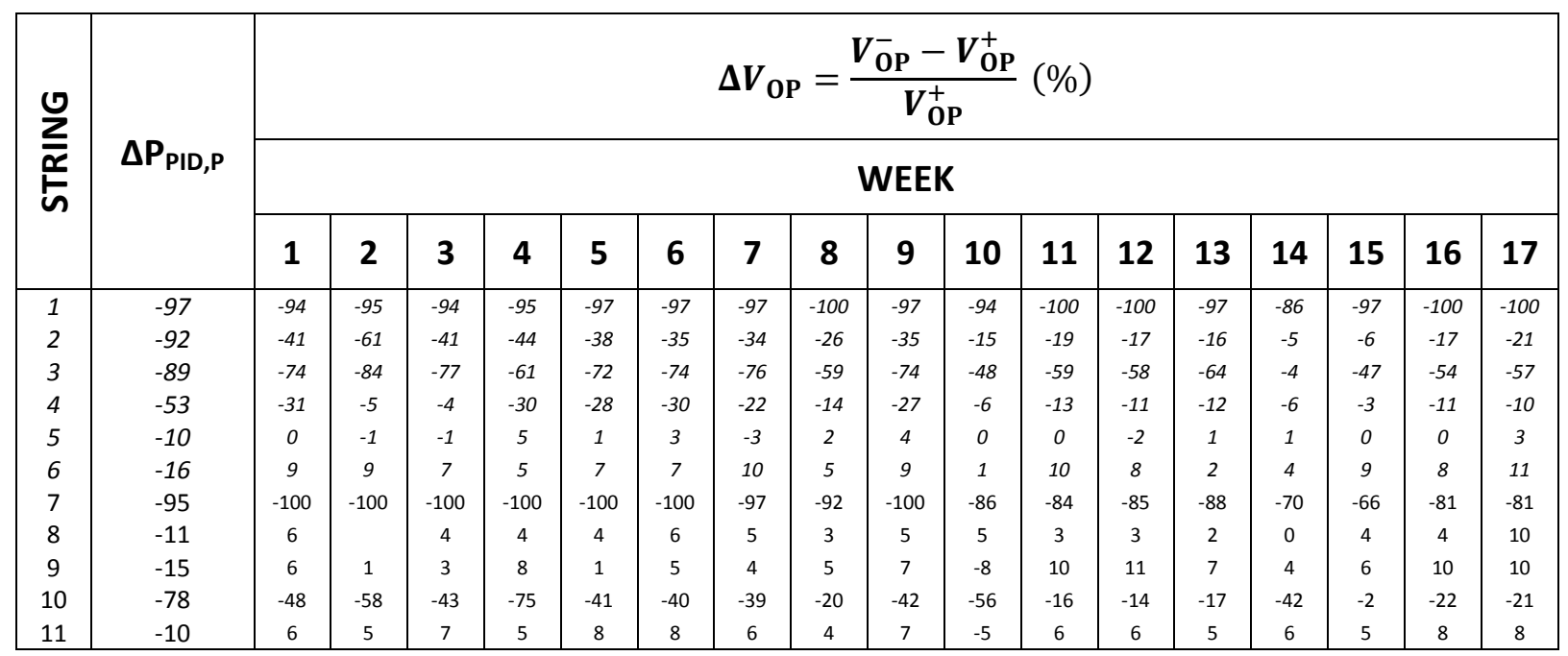

Table 2. Operating voltage difference (\%) between two PV modules located at the extremes of 11 strings of the PV plant being studied (PID unaffected module at positive pole, laboratory PID degraded module at the negative pole). First column indicates the number of the string. Second column, $\Delta \mathrm{P}_{\mathrm{PID}, \mathrm{P}}$, contains the decrease in power of the modules previously degraded in laboratory PID testing. Rows in italic -1 to 6 - are related to the strings connected to an inverter with an anti-PID device.

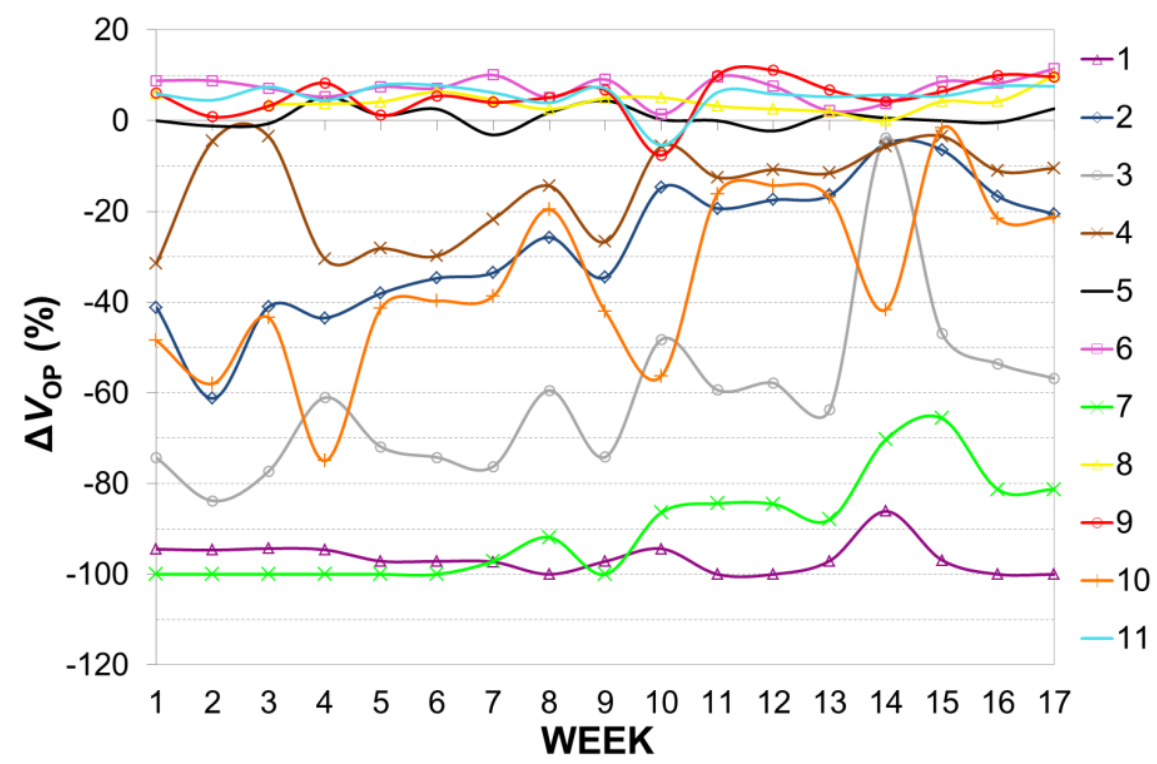

Fig. 7. Evolution of the operating voltage difference, $\Delta V_{\mathrm{OP}}$, between the two extreme modules of the 11 strings being studied. 


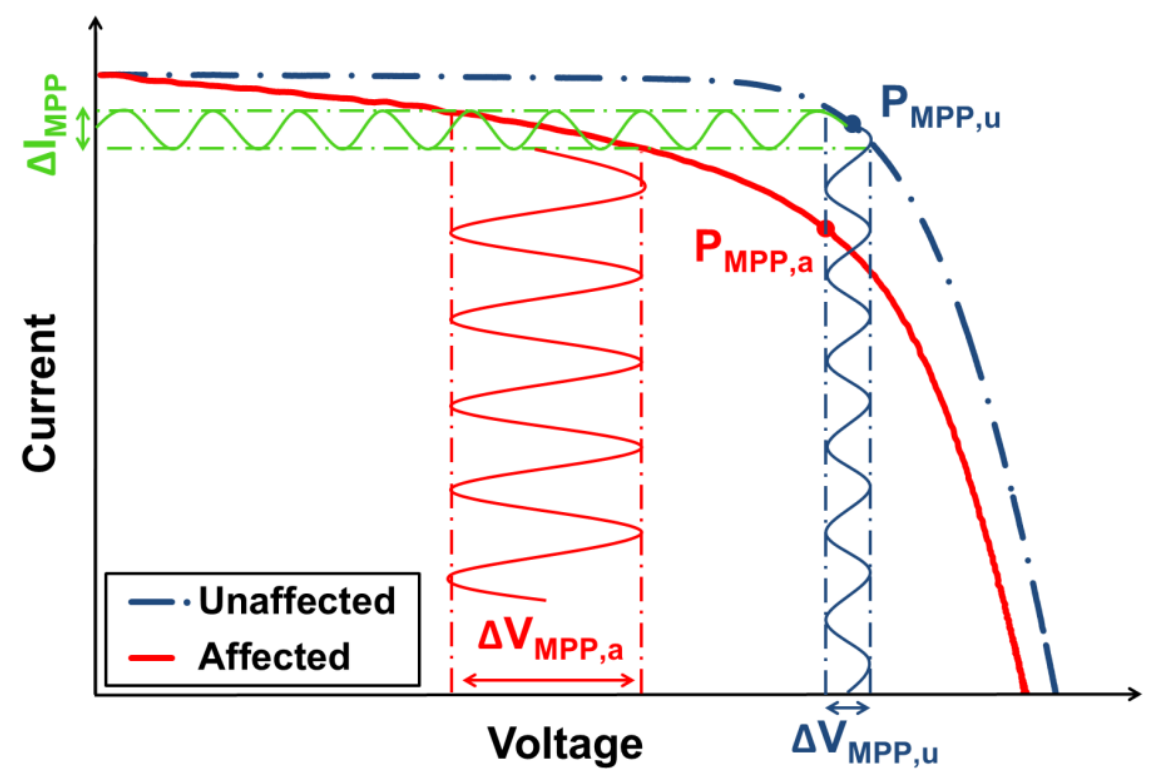

Fig. 8. I-V curves of an unaffected (dashed blue line) and a PID affected (continuous red line) module. The MPP are marked for each module. It is assumed that the affected module is connected in series with a large number of unaffected ones and the resulting string is connected to an inverter able to impose the MPP. Because of the disproportion between the number of defective and nondefective modules, the operating current of the whole string is close to that corresponding to the MPP of the unaffected modules. Signal " $\Delta \mathrm{I}_{\mathrm{MPP}}$ " (green sinusoid) represents the current oscillations around the operating current as a result of the MPP tracking strategy of the inverter. Signal " $\Delta \mathrm{V}_{\mathrm{MPP}, \mathrm{u}}$ " (blue sinusoid) and " $\Delta \mathrm{V}_{\mathrm{MPP}, \mathrm{a}}$ " (red sinusoid) represent the corresponding voltage oscillations related to that current oscillations for the unaffected and the affected modules. Voltage excursions are clearly greater in the module affected by PID.

Two other results deserve further comment. On the one hand, the differences observed in the degradation between the output of the PID induction process and the beginning of the in-the-field experiment (columns "PID degradation..." and "WEEK 1" in Table 2) reflect the natural PID recovery during the three weeks the modules were kept in the dark for transportation from the laboratory to the plant. On the other hand, Fig. 9 distinguishes between the modules (a) with and (b) without anti-PID devices. The number of degraded samples connected to inverters without anti-PID devices is low (only 2), but it seems that recovery in both cases is similar. It would be needed testing more modules in both situations to stablish if anti-PID devices are useful in this case.

It should be emphasized that this method using modules with previously artificially induced PID is valid but has limited statement. Results are only representative for the investigated module-type and location. In case of positive evolution, i.e. PID recovery, an appropriate PID resistivity can be verified. However, if the module does not recover or degrades further it is not sure that an intact module without artificially induced PID will show PID during its service life. 


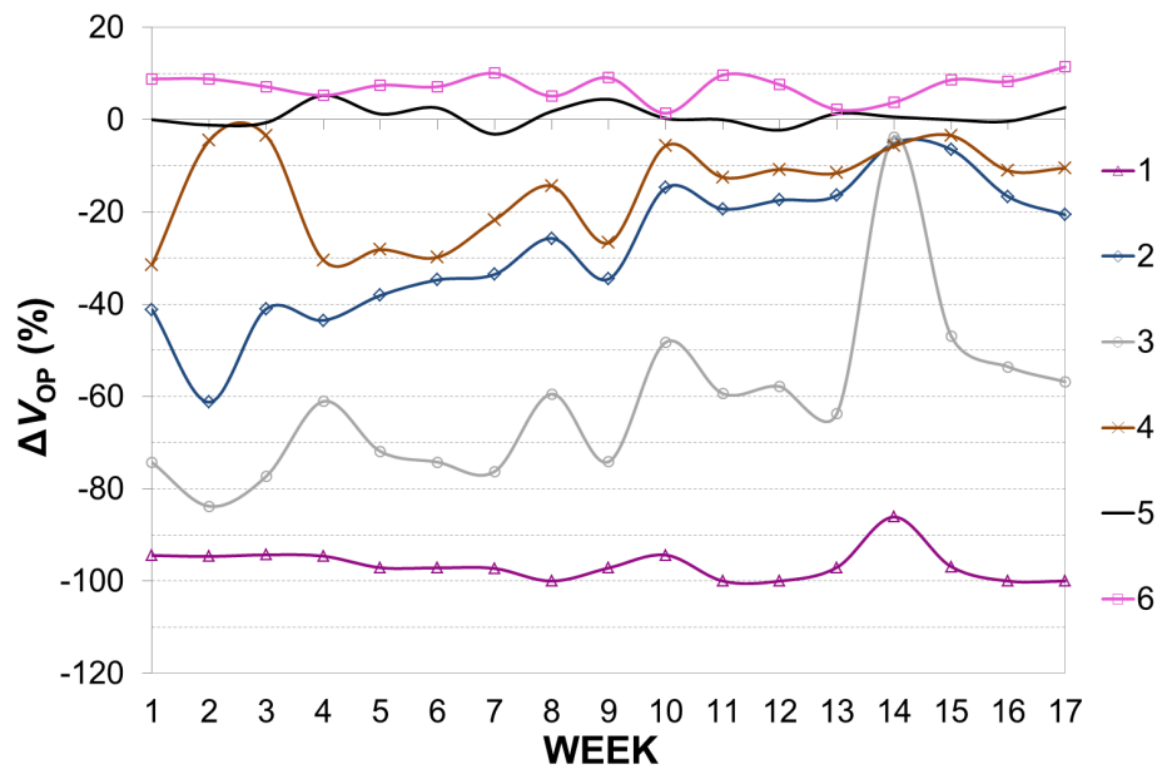

(a)



(b)

Fig. 9. Evolution of the operating voltage difference, $\Delta V_{\mathrm{OP}}$, between the two extreme modules of the 11 strings being studied. (a) Modules with anti-PID devices. (b) Modules without anti-PID devices. 


\section{CONCLUSIONS}

PID has been reviewed by focusing on its kinetics in PV plants made up of standard c-Si modules at floating voltage arrays. PID is due to the leakage currents, which transport $\mathrm{Na}^{+}$ions present in the soda-lime front glass to the active layers of the cells, between negatively-polarized cells and the grounded module frame. The PID formation process is particularly significant in the early morning when the front glass is covered with dew, which increases the conductivity of the path of the leakage currents. Later, irradiance makes dew evaporate, thus decreasing conductivity and PID recovery takes place aided by the increase in temperature and irradiance. The final in-the-field occurrence of PID depends on the balance between PID formation and recovery forces, which depends not only on the characteristics of the PV module but also on the climatic conditions of the location. Current standards addressing PID in PV modules only consider PID formation but not PID recovery processes, so the in-the-field occurrence of PID remains an open question.

Two in-the-field PID-related experiences into commercial PV plants have been presented as experimental support for two different propositions. On the one hand, the comparison of the module voltage during normal operating conditions at the two extremes of the same string is proposed as a particularly suitable method for detecting PID. It is easy to carry out and not only provides a clearer evidence of PID occurrence, but also a more accurate way to quantify the effective power losses caused by this phenomenon in the modules affected. Besides, it is also susceptible to on-line implementation for continuous PID surveillance, which is important for detecting PID before irreversible electrochemical corrosion takes place. On the other hand, the monitoring and analysis of the in-the-field PID evolution in modules with previously artificially induced PID, once installed in the negative pole of the PV arrays at the location concerned, is proposed as a method for predicting the long-term occurrence of PID. Positive evolution (increases in power) is interpreted as the predominance of PID recovery over PID formation processes suggesting that PID will not occur.

\section{ACKNOWLEDGEMENTS}

This work was supported by the FP7 European Program (Energy) through the project PhotoVoltaic Cost reduction, Reliability, Operational performance, Prediction and Simulation (PVCROPS), Project reference 308468 (http://www.pvcrops.eu). 


\section{REFERENCES}

[1] Luo W, Khoo YS, Hacke P, Naumann V, Lausch D, Harvey SP, Singh JP, Chai J, Wang Y, Aberle AG, Ramakrishna S. Potential-induced degradation in photovoltaic modules: a critical review. Energy and Environmental Science (RSC Publishing), 10, 43-68, (2017). doi: 10.1039/C6EE02271E

[2] Hacke P, Terwilliger K, Smith R, Glick S, Pankow J, Kempe M, Bennet SKI, Kloos M. System voltage Potential-Induced Degradation mechanisms in PV modules and methods for test. $37^{\text {th }}$ IEEE Photovoltaic Specialist Conference, Seattle (USA) (2011). doi: 10.1109/PVSC2011.6186079

[3] Colli A. The role of sodium in photovoltaic devices under high voltage stress: $A$ holistic approach to understand unsolved aspects. Renewable Energy, 60, 162-168 (2013). doi:10.1016/j.renene.2013.05.007

[4] Reed S, SMA America. Cited in Pickerel K. Can we trust PID-free solar panel labeling? http://www.solarpowerworldonline.com/2015/03/can-we-trust-pid-free-labeling/ [accesed 01.05.2017]

[5] (C) Fraunhofer ISE: Photovoltaics Report, updated: 12 July 2017.

[6] Jäger-Waldau A. PV Status Report 2016. Joint Research Centre (JRC). EUR 28159 EN. doi: 10.2790/682995

[7] Technology Roadmap. Solar Photovoltaic Energy. 2014 Edition. International Energy Agency (IEA).

[8] Ardani K., Margolis R. 2010 Solar Technologies Market Report. National Renewable Energy Laboratory (NREL). November 2011.

[9] Hoffman AR, Ross RG. Environmental qualification testing of terrestrial solar cell modules. $13^{\text {th }}$ IEEE Photovoltaic Specialist Conference, Washington DC (USA), 835-842 (1978).

[10] Osterwald CR, McMahon TJ. History of accelerated and qualification testing of terrestrial photovoltaic modules: a literature review. Prog. Photovolt: Res. Appl, 17, 11-33 (2009) doi: 10.1002/pip.861

[11] Ross Jr RG, Mon GR, Wen LC, Sugimura RS. Measurement and characterization of voltageand current-induced degradation of thin-film photovoltaic modules. Solar Cells, 27, 289-298 (1989).

[12] Swanson R, Cudzinovic M, DeCeuster D, Desai V, Jürgens J, Kaminar M, Mulligan W, Rodrigues-Barbarosa L, Rose D, Smith D, Terao A, Wilson K. The surface polarization effect in high-efficiency silicon solar cells. $15^{\text {th }}$ International Photovoltaic Science and Engineering Conference, Shangai (China) (2005).

[13] Naumann V, Geppert T, Großer S, Wichmann D, Krokoszinski HJ, Werner M, Hagendorf C. Potential-induced degradation at interdigitated back contact solar cells. Energy Procedia, 55, 498-503 (2014). doi: 10.1016/j.egypro.2014.08.015

[14] Pingel S, Frank O,Winkler M, Daryan S, Geipel T, Hoenhe H, Berghold J. Potential induced degradation of solar cells and panels. $35^{\text {th }}$ IEEE Photovoltaic Specialist Conference, Honolulu (USA), 2817-2822 (2010). doi: 10.1109/PVSC-1010.5616823 
[15] Hacke P, Terwilliger K, Glick S, Trudell D, Bosco N, Johnston S, Kurtz S. Test-to failure of crystalline silicon modules. $35^{\text {th }}$ IEEE Photovoltaic Specialist Conference, Honolulu (USA), 244-250 (2010). doi: 10.1109/PVSC-1010.5614472

[16] Naumann V, Hagendorf C, Grosser S, Werner M, Bagdahn J. Micro structural root cause analysis of Potential Induced Degradation in c-Si solar cells. Energy Procedia, 27, 1-6 (2012). doi: 10.1006/j.egypro.2012.07.020

[17] Bauer J, Naumann V, Großer S, Hagendorf C, Schütze M, Breitenstein O. On the mechanism of potential-induced degradation in crystalline silicon solar cells. Phys. Status Solidi RRL, 6, 331-333 (2012). doi: 10.1002/pssr.201206267

[18] Naumann V, Lausch D, Graff A, Werner M, Swatek S, Bauer J, Hähnel A, Breitenstein O, Großer S, Bagdahn J, Handendorf C. The role of stacking faults for the formation of shunts during potential-induced degradation of crystalline Si solar cells. Phys. Status Solidi RRL, 7, 315-318 (2013). doi:10.1002/pssr.201307090

[19] Naumann V, Lausch D, Hähnel A, Bauer J, Breitenstein O, Graff A, Werner M, Swatek S, Großer S, Bagdahn J, Hagendorf C. Explanation of potential-induced degradation of the shunting type by Na decoration of stacking faults in Si solar cells. Solar Energy Materials and Solar Cells, 120, 383-389 (2014). doi: 10.1016/j.solmat.2013.06.015

[20] Ziebarth B, Mrovec M, Elsässer C, Gumgsch P. Potential-induced degradation in solar cells: electronic structure and diffusion mechanism of sodium in stacking faults of silicon. Journal of Applied Physics, 116, (2014). doi:10.1063/1.4894007

[21] Hara K, Jonai S, Masuda A. Potential-induced degradation in photovoltaic modules based on n-type single crystalline Si solar cells. Solar Energy Materials and Solar Cells, 140, 361-365 (2015). doi: 10.1016/j.solmat.2015.04.037

[22] Berghold J, Frank O, Hoehne H, Pingel S, Richardson B, Winkler M. Potential Induced Degradation of solar cells and panels, $25^{\text {th }}$ EUPVSEC, Valencia (Spain), 3753-3759, (2010). doi: 10.4229/25thEUPVSEC2010-4BO.9.5

[23] Pingel S, Janke S, Frank O. Recovery methods for modules affected by Potential Induced Degradation (PID). 27 $7^{\text {th }}$ EUPVSEC, Frankfurt (Germany), 3379-3383 (2012). doi: 10.4229/27thEUPVSEC2012-4BV.2.46

[24] Koch S, Berghold J, Hinz C, Krauter S, Grunow P. Improvement of a prediction model for Potential Induced Degradation by better understanding the regeneration mechanism. $31^{\text {st }}$ EUPVSEC, Hamburg (Germany), 1813-1820, (2015). doi: 10.4229/EUPVSEC20152015$5 C 0.16 .2$

[25] Del Cueto JA, McMahon TJ. Analysis of leakage currents in photovoltaic modules under highvoltage bias in the field. Prog. Photovolt: Res. Appl, 10, 15-28 (2002). doi: 10.1002/pip.401

[26] Dhere NG, Shiradkar NS, Schneller E. Evolution of leakage current paths in mc-Si modules from leading manufacturers undergoing high-voltage bias testing. IEEE Journal of Photovoltaics, 4, 654-658, (2014) doi: 10.1109/JPHOTOV.2013.2294764

[27] Koehl M, Hoffmann S. Impact of rain and soiling on potential induced degradation. Prog. Photovolt: Res. Appl. 24, 1304-1309 (2016). doi: 10.1002/pip.2786 
[28] Lechner P, Hummel S, Schnepf J. Evaluation of recovery methods after Potential Induced Degradation of PV modules. $31^{\text {st }}$ EUPVSEC, Hamburg (Germany), 1821-1824, (2015). doi: 10.4229/EUPVSEC20152015-5CO.16.3

[29] Yamaguchi S, Masuda A, Ohdaira K. Behavior of the potential-induced degradation of photovoltaic modules fabricated using flat mono-crystalline silicon cells with different surface orientations. Japanese Journal of Applied Physics, 55, 04ES14, (2016). doi: 10.7567/JJAP.55.04ES14

[30] Koch S, Nieschalk D, Berghold J, Wendlandt S, Krauter S, Grunow P. Potential Induced Degradation effects on crystalline silicon cells with various antireflective coating. $27^{\text {th }}$ EUPVSEC, Frankfurt (Germany), 1985-1990, (2012) doi: 10.4229/27thEUPVSEC2012-2CV.7.3

[31] Mishina K, Ogishi A, Ueno K, Doi T, Hara K, Ikeno N, Imai D, Saruwatari T, Shinohara M, Yamazaki T, Ogura A, Ohshita $\mathrm{Y}$, Masuda A. Investigation on antireflection coating for high resistance to potential-induced degradation. Japanese Journal of Applied Physics, 53, 03CE01 (2014), doi: 10.7567/JJAP.53.03CE01

[32] Mehlich H, Decker D, Scheit U, Uhlig M, Frigge S, Runge M, Heinze B, Sperlich HP, Mai J, Schlemm H, Vetter E, Höhne J, Reichel S, Stein W. A new nethods for high resistance against Potential Induced Degradation. $27^{\text {th }}$ EUPVSEC, Frankfurt (Germany), 3411-3413 (2012) doi: 10.4229/27thEUPVSEC2012-4BV.2.52

[33] Nagel H, Saint-Cast P, Glatthaar M, Glunz SW. Inline Processes for the stabilization of p-type crystalline Si solar cells against Potential-Induced Degradation. $29^{\text {th }}$ EUPVSEC, Amsterdam (The Netherlands), 2351-2355 (2014). doi: 10.4229/EUPVSEC20142014-5C0.14.5

[34] Kapur J, Bennett A, Norwood J, Hamzavytehrany B, Kueppenbender I. Tailoring ionomer encapsulants as a low cost solution to Potential Induced Degradation. $28^{\text {th }}$ EUPVSEC, Paris (France), 476-479 (2013). doi: 10.4229/28thEUPVSEC2013-1CV.2.10

[35] Koch S, Berghold J, Okoroafor O, Krauter S, Grunow P. Encapsulation influence on the Potential Induced Degradation of crystalline silicon cells with selective emitter structures. $27^{\text {th }}$ EUPVSEC, Frankfurt (Germany), 1991-1995 (2012). doi: 10.4229/27thEUPVSEC20122CV.7.4

[36] Schulze SH, Apel A, Meitzer R, Schak M, Ehrich C, Schneider J. Influence of polymer properties on Potential Induced Degradation of PV-modules. $28^{\text {th }}$ EUPVSEC, Paris (France), 503-507 (2013). doi:10.4229/28thEUPVSEC2013-1CV.2.21

[37] Reid C, Ferrigan S, Fidalgo I, Woods J. Contribution of PV encapsulant composition to reduction of Potential Induce Degradation (PID) of crystalline silicon PV cells. $28^{\text {th }}$ EUPVSEC, Paris (France), 3340-3346 (2013). doi:10.4229/28thEUPVSEC2013-4AV.5.49

[38] Masuda A, Hara Y, Jonai S. Consideration on Na diffusion and recovery phenomena in potential-induced degradation for crystalline Si photovoltaic modules. Japanese Journal of Applied Physics, 55, 02BF10 (2016), doi: 10.7567/JJAP.55.02BF10

[39] Kambe M, Hara K, Mitairi K, Takeda S, Fukawa M, Ishimaru N, Kondo M. PID-free C-Si PV module using alminosilicate chemically strengthened glass. $28^{\text {th }}$ EUPVSEC, Paris (France), 2861-2864 (2013). doi:10.4229/28thEUPVSEC2013-4CO.10.6 
[40] Nagel H, Pfeiffer R, Raykov A, Wangemann K. Lifetime warranty testing of crystalline silicon modules for Potential-Induced Degradation. $27^{\text {th }}$ EUPVSEC, Frankfurt (Germany), 3163-3166 (2012). doi:10.4229/27thEUPVSEC2012-4DO.6.4

[41] Mathiak G, Schweiger M, Herrmann W, Eikelboom E, Sedlacek M, Al Rifai MH. Potential Induced Degradation-comparison of different test methods and low irradiance performance

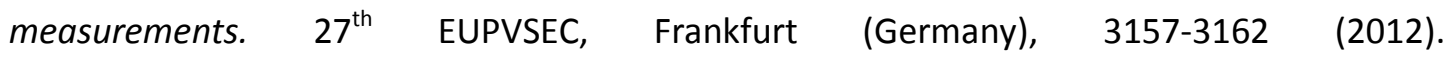
doi:10.4229/27thEUPVSEC2012-4DO.6.3

[42] Hacke P, Smith R, Terwilliger K, Glick S, Jordan D, Johnston S, Kempe M, Kurtz S. Testing and analysis for lifetime prediction of crystalline silicon PV modules undergoing degradation by system voltage stress. IEEE Journal of Photovoltaics, 3, 246-253 (2012). doi: 10.1109/JPHOTOV.2012.2222351

[43] Hacke P, Spataru S, Terwilliger K, Perrin G, Glick S, Kurtz S, Wohlgemuth J. Accelerated testing and modelling of Potential-Induced Degradation as a function of temperature and relative humidity. IEEE Journal of Photovoltaics, 5, 1549-1553 (2015). doi: 10.1109/JPHOTOV.2015.2466463

[44] IEC-TS-62804-1:2015. Photovoltaic (PV) modules - Test methods for the detection of PIDPart 1: Crystalline Silicon

[45] Hacke P, Terwilliger K, Koch S, Weber T, Berghold J, Hoffmann S, Koehl M, Dietrich S, Ebert M, Mathiak G. Results of IEC 62804 draft round robin testing. NREL/PR-5200-60493 (2013).

[46] Koentopp MB, Kröber M, Taubitz C. Towards a PID test standard: understanding and modelling of laboratory tests and field progression. IEEE Journal of Photovoltaic, 6, 252-257 (2016).doi: 10.1109/JPHOTOV.2015.2487828

[47] Kang K, Kim B, Park S, Chang S. Lifetime sarranty test method considering Potential Induced Degradation recovery behavior. $32^{\text {nd }}$ EUPVSEC, Munich (Germany), 1884-1887 (2016). doi: 10.4229/EUPVSEC20162016-5BV.1.27

[48] Oh J, Bowden S, TamizhMani G. Potential-Induced Degradation (PID): incomplete recovery of shunt resistance and quantum efficiency losses. IEEE Journal of Photovoltaics, 5, 15401548(2015). doi: 10.1109/JPHOTOV.2015.2459919

[49] Del Cueto JA, Rummel SR. Degradation of photovoltaic modules under high voltage stress in the field. Optics and Photonics Conference. Proc. SPIE 7773 Reliability of Photovoltaic cells, modules, components and systems III 77730J, San Diego (USA) (2010). doi: $10.1117 / 12.861226$

[50] Hoffmann S, Koehl M. Effect of humidity and temperature on the potential-induced degradation. Prog. Photovolt: Res. Appl, 22, 173-179 (2014). doi: 10.1002/pip.2238

[51] Raykov A, Nagel H, Amankwah DJ, Bergholz W. Climate model for Potential-Induced Degradation of crystalline silicon photovoltaic modules. $27^{\text {th }}$ EUPVSEC, Frankfurt (Germany), 3399-3404 (2012). doi: 10.4229/27thEUPVSEC2012-4BV.2.50

[52] Taubitz C, Kröber M, Schütze M, Koentopp MB. Kinetic description and modelling of Potential Induced Degradation. $28^{\text {th }}$ EUPVSEC, Paris (France), 3321-3323 (2013). doi: 10.4229/28thEUPVSEC2013-4AV.5.45

[53] Taubitz C, Schütze M, Kröber M, Koentopp MB. Potential Induced Degradation: model calculations and correlation between laboratory test and outdoor ocurrence. $29^{\text {th }}$ EUPVSEC, 
Amsterdam (The Netherlands), 2490-2494 (2014). doi: 10.4229/EUPVSEC201420145DO.11.3

[54] Chliaoutakis A, Protogeropoulos C, Karelas G, Doukas E, Talfanidou M, Papaioannou E, Foukarakis E, Zouboulis I, Tsimpris P. Potential Induced Degradation (PID) diagnosis, treatment and module recovery in a grid connected photovoltaic (PV) power station in Greece. $\quad 31^{\text {st }}$ EUPVSEC, Hamburg (Germany), 2167-2172 (2015). doi: 10.4229/EUPVSEC20152015-5BV.2.3

[55] Braisaz B, Radouane K. PID Results at low irradiances on c-Si modules. $40^{\text {th }}$ IEEE Photovoltaic Specialist Conference, Denver (USA), 1993-1996 (2014). doi: 10.1109/PVSC.2014.6925316

[56] Hinz C, Koch S, Weber T, Berghold J. Regeneration of Potential Induced Degradation affected modules. $\quad 32^{\text {nd }}$ EUPVSEC, Munich (Germany), 1552-1557 (2016). doi: 10.4229/EUPVSEC20162016-5BO.11.1

[57] Hu Y, Ni P, Wei Q, Li C, Mou Z, Hu L, Yan Y, Liu C, Lu J, Wu C.. Recovery method for solar modules affected by Potential Induced Degradation in utility-scale solar plants, $32^{\text {nd }}$ EUPVSEC, Munich (Germany), 1912-1914, (2016). doi: 10.4229/EUPVSEC20162016-5BV.1.35

[58] Martínez-Moreno F, Lorenzo E, Muñoz J, Parra R, Espino T. On-site tests for the detection of potential induced degradation in modules. $28^{\text {th }}$ EUPVSEC, Paris (France), 3313-3317 (2013). doi: 10.4229/28thEUPVSEC2013-4AV.5.43

[59] IEC 60891:2009. Photovoltaic devices - Procedures for temperature and irradiance corrections to measured I-V characteristics. 